\title{
Properties of athletic mouth protectors and materials
}

\author{
R. G. CRAIG \& W. C. GODWIN School of Dentistry, University of Michigan, Ann Arbor, MI, USA
}

\begin{abstract}
SUMMARY The properties of a variety of mouth protectors and sheet materials used to fabricate custom mouth protectors were determined in order to recommend limits for a specification. Hardness, water sorption, water solubility, impact absorption,
\end{abstract}

and tear strength were measured, and limits for these properties were suggested.

KEYWORDS: hardness, impact absorption, tear strength, standards

\section{Introduction}

A variety of athletic mouth protectors has been developed over the years including stock, boil-and-bite, latex rubber, hand-and-vacuum-formed from thermoplastic sheets, and vacuum-formed from laminated thermoplastic sheets.

The physical properties of materials for custom-made mouth protectors were reported in an early publication by Craig and Godwin (1967). The materials evaluated were polyurethane, polyvinylacetate-polyethylene, rubber latex and a vinyl plastisol. That publication reviewed the literature related to the incidence of oral injuries in contact sports and the effectiveness of various types of mouth protectors. A summary of the results of these studies concluded that any of the mouth protectors would reduce oral injuries. Although there was no agreement as to the superiority of stock or mouth-formed versus custom-made mouth protectors, opinion surveys of athletes showed a preference for custom-made protectors based on cleanliness, lack of taste and odour, retention, durability, speaking and comfort.

In spite of the fact that mouth protectors have been in use since the 1950s, no American Dental Association/American National Standards Institute or American Standards for Testing Materials specification for mouth protectors or materials has been approved, although they are being developed.

The present study of current mouth protectors and materials was undertaken to provide a basis for estab- lishing requirements for athletic mouth protectors and materials used to fabricate such appliances.

\section{Materials and methods}

\section{Materials}

The mouth protectors evaluated and their suppliers are listed in Table 1, and the thermoplastic sheets used to fabricate custom mouth protectors are listed along with their suppliers in Table 2 . The stock and mouth-formed protectors listed in Table 1 do not include all products, but do represent an adequate sample of the types available.

Some of the mouth protectors in Table 1 have a softer thermoplastic liner and a harder shell, and some do not. These protectors are heated in hot water followed by immersion in cold water to cool the surface before placing them in the mouth and biting down to make an impression of the biting surface of the teeth. Most of the thermoplastic sheets are copolymers of vinyl acetate and ethylene. Softer sheets are made from copolymers containing fewer ethylene segments.

\section{Methods}

The test methods used to evaluate thermoplastic sheets included (i) Shore 'A' hardness, (ii) tear strength, (iii) water sorption and (iv) impact testing, while the tests conducted on stock, mouth-formed, and vacuumformed protectors were (i) Shore 'A' hardness, (ii) water sorption and (iii) impact testing. 
Table 1. Stock and mouth-formed mouth protectors

\begin{tabular}{ll}
\hline $\begin{array}{l}\text { Mouth } \\
\text { protector }\end{array}$ & Supplier \\
\hline Bop Stopper & Be Safe Products Inc., Roanoke, VA, USA \\
Den Pak & 75 Research Drive, Strathford, CT, USA \\
Doublegard & Masel Industries Inc., Bristol, PA, USA \\
Jesco & Jesco Products, Summerville, SC, USA \\
Scott AllSports & Scott All-Sports Inc., West Monroe, LA, USA \\
Shield & Brimms Inc., Tonawanda, NY, USA \\
Tru-Fit & True-Fit Marketing Corporation, Lynn, MA, USA \\
Shock Doctor & E-Z Gard Industries Inc., Minneapolis, MN, USA \\
\hline
\end{tabular}

Table 2. Thermoplastic sheets for fabrication of athletic mouth protectors

\begin{tabular}{ll}
\hline Product & Supplier \\
\hline Glidewell & Glidewell Laboratories, Newport Beach, CA, USA \\
Play Safe & Glidewell Laboratories, Newport Beach, CA, USA \\
Proform & Dental Resources Inc., Delano, MN, USA \\
Proform & Dental Resources Inc., Delano, MN, USA \\
$\quad$ Laminate & \\
Volara (white) & Voltek, Lawrence, MA, USA \\
WorldWide & WorldWide Dental Division, Clearwater, FL, USA \\
StaGuard & Buffalo Dental Manufacturing, Syosset, NY, USA \\
\hline
\end{tabular}

Shore ' $A$ ' hardness

A shore Type 'A' Durometer* according to ASTM Durometer Test D2240 [American Society for Testing Materials (ASTM) 1994a] was used to measure hardness. The instrument has a blunt-pointed indenter $0.8 \mathrm{~mm}$ in diameter that tapers to a cylindrical shaft of $1.6 \mathrm{~mm}$. The indenter is attached by a lever to a pointer which indicates the hardness on a scale of 0-100. The Shore ' $\mathrm{A}$ ' hardness was determined on as flat and as thick a surface as possible. The indenter was pressed rapidly into the surface, the maximum instantaneous value was recorded. Both sheets and protectors were stored in water at $37{ }^{\circ} \mathrm{C}$ for 7 days, the hardness measured as soon as they were removed from the water bath. Five hardness measurements were made in separate areas to determine the average Shore ' $\mathrm{A}$ ' hardness.

\section{Tear strength}

The ASTM test for the tear resistance of rubber D624 (ASTM 1994b) with tear die 'C', was used. Test specimens were stamped from sheets using a steel die conforming to the dimensions listed in ASTM D624.

*The Shore Instrument and Manufacturing Co., Jamaica, NY, USA.
The cutting edges of the die were sharp and free of nicks, and the apex of the $90^{\circ}$ notch was honed to form a sharp corner.

Mouth protector sheets were placed on light weight cardboard supported by a smooth block of hardwood. The cutting edges of the die were positioned perpendicular to the sheets, and the anvil of the die was struck with a heavy hammer to cut and tear samples with a single blow. If the blade did not cut through the sheet with a single blow, the die was not moved and additional blows were struck. The thickness was measured in the area of the notch, and samples were stored in $37^{\circ} \mathrm{C}$ water until equilibrium was reached. Specimens were removed from the water bath and immediately clamped in a universal testing machine and loaded in tension at $50 \mathrm{~cm} \mathrm{~min}^{-1}$ until rupture. The maximum load at rupture divided by the thickness yielded the tear strength in $\mathrm{N} \mathrm{cm}^{-1}$. Five specimens were tested to obtain the mean value and to calculate the standard deviation (s.d.).

\section{Water sorption}

Water sorption on sheet materials and mouth protectors was determined after specimens had come to constant weight (within $0.001 \mathrm{~g}$ ) in a desiccant containing $\mathrm{CaSO}_{4}$ drying agent (usually 5 days). Dried specimens were placed in $37{ }^{\circ} \mathrm{C}$ water and removed daily, dried quickly with a soft tissue, and weighed. This process was repeated until two successive weights within $0.001 \mathrm{~g}$ were obtained. Five specimens of sheet materials were used to calculate the mean weight percentage of water sorbed and the standard deviations. Various numbers of mouth protectors, 2-7, for each brand were used.

It should be noted that water solubility was determined on sheets for mouth protectors from two suppliers by drying water sorption samples again to equilibrium in the desiccant. Average solubility was $0.003 \%$, and because of the low values, further testing of additional products was discontinued.

\section{Impact testing}

A pendulum impact instrument (in this study, a 10-in-pound Tinius Olsen Impact Tester with a Charpy impact pendulum) capable of providing an impact of $113 \mathrm{~N}-\mathrm{cm}$ and having a striking surface of the arm of the pendulum of $1 \mathrm{~cm}$ wide $\times 1.5 \mathrm{~cm}$ long. The instrument had clamps and mounting for sheets or highstrength stone models supporting the custom-made 
Table 3. Properties of polymer sheets for athletic mouth protectors

\begin{tabular}{|c|c|c|c|c|c|}
\hline \multirow[b]{2}{*}{ Product } & \multirow{2}{*}{$\begin{array}{l}\text { Shore 'A' hardness } \\
\text { at } 37^{\circ} \mathrm{C}\end{array}$} & \multirow{2}{*}{$\begin{array}{l}\text { Water sorption } \\
\text { wt } \% \text { at } 37^{\circ} \mathrm{C}\end{array}$} & \multirow{2}{*}{$\begin{array}{l}\text { Tear strength } \\
\mathrm{N} \mathrm{cm}^{-1} \text { at } 37{ }^{\circ} \mathrm{C}\end{array}$} & \multicolumn{2}{|c|}{ Impact tests, room temperature } \\
\hline & & & & $\%$ absorbed & $\mathrm{N}-\mathrm{cm}$ absorbed \\
\hline \multicolumn{6}{|l|}{ Glidewell } \\
\hline Thin & $76 \cdot 8(1 \cdot 3)$ & $0 \cdot 14(0 \cdot 01)$ & & $90.6(0.5)$ & $102 \cdot 4(0 \cdot 6)$ \\
\hline Thick & $76 \cdot 2(1 \cdot 3)$ & $0 \cdot 14(0.01)$ & $565(40)$ & $88 \cdot 0(0 \cdot 7)$ & $99 \cdot 4(0 \cdot 8)$ \\
\hline $\mathrm{PVC}$ & $95 \cdot 0(0)$ & $0.30(0.02)$ & & & \\
\hline \multicolumn{6}{|l|}{ Play Safe } \\
\hline Thin & $79 \cdot 7(0 \cdot 5)$ & $0.22(0.01)$ & $471(4)$ & $88 \cdot 8(1 \cdot 0)$ & $100 \cdot 3(1 \cdot 1)$ \\
\hline Thick & $75 \cdot 2(0 \cdot 4)$ & $0.25(0.01)$ & $416(20)$ & & \\
\hline Proform & $80 \cdot 8(0 \cdot 7)$ & $0.23(0.03)$ & $410(14)$ & $80 \cdot 6(1 \cdot 1)$ & $91 \cdot 1(1 \cdot 2)$ \\
\hline \multicolumn{6}{|c|}{ Proform Laminates } \\
\hline Clear side & $74 \cdot 6(1 \cdot 4)$ & $0.15(0.01)$ & $325(16)$ & $83 \cdot 6(0 \cdot 6)^{*}$ & $94.5(0 \cdot 7)^{*}$ \\
\hline Colour side & $75 \cdot 8(2 \cdot 0)$ & & & & \\
\hline Volara (white) & $25 \cdot 8(0 \cdot 8)$ & $4 \cdot 1(0 \cdot 3)$ & $68.0(1.9)$ & $87 \cdot 1(1 \cdot 8)$ & $98 \cdot 4(2 \cdot 0)$ \\
\hline WorldWide & $79 \cdot 1(1 \cdot 8)$ & $0 \cdot 19(0 \cdot 04)$ & $414(37)$ & $88 \cdot 3(0 \cdot 8)$ & $99 \cdot 8(0 \cdot 9)$ \\
\hline
\end{tabular}

${ }^{*}$ At $37{ }^{\circ} \mathrm{C}, 87 \cdot 3(0 \cdot 6) \%$ absorbed and $98 \cdot 6(0 \cdot 7) \mathrm{N}-\mathrm{cm}$ absorbed.

mouth protectors. The high-strength stone models were obtained by duplicating a maxillary Dentaform model. In the testing of stock or mouth-formed protectors, tape was wrapped around the periphery to form a dam, and the protector was poured in high-strength stone. After setting, the base and heel of the high-strength stone were trimmed perpendicular using a standard dental laboratory model trimmer. The specimens were then allowed to stand until the dry strength of the highstrength stone had been reached. After mounting on the impact machine, the pendulum was raised so it provided an impact of $113 \mathrm{~N} \mathrm{~cm}$ and released. The amount of rebound was recorded and the percentage and the $\mathrm{N}-\mathrm{cm}$ of the impact absorbed were calculated. Testing was done at room temperature for convenience as testing of Proform ${ }^{\dagger}$ sheets at $37{ }^{\circ} \mathrm{C}$ showed only a $4 \%$ increase in the percentage of impact absorbed over room temperature.

\section{Results}

The property data for (i) polymer sheets, (ii) custom fabricated mouth protectors and (iii) stock and mouthformed mouth protectors are presented in Tables 3-5, respectively.

The Shore ' $A$ ' hardness values for most of the sheets were from 75 to 80 except for the PVC poly(vinyl chloride) insert for Glidewell ${ }^{\ddagger}(95 \cdot 0)$ and the foam

${ }^{\dagger}$ Dental Resources Inc., Delano, MN, USA.

${ }^{\ddagger}$ Glidewell Laboratories, Newport Beach, CA, USA. material Volara ${ }^{\S}(25 \cdot 8)$. The hardness of the shells of the stock or mouth-formed mouth protectors varied from 57 to 81 with low values of 32 for Bop Stoppers, , I 57 for Shield Youth, and 63 for Den Pak; ${ }^{* *}$ the remainder had hardness values from 73 to 81 . The hardness of liners of Den Pak (26), Doublegard ${ }^{++}(50)$, Shield $2000^{\ddagger \ddagger}(47 \cdot 3)$, and Shock Doctor ${ }^{\S \S}(50)$ were, as expected, substantially lower.

The water sorption values for all sheet materials was low, $<0.3 \mathrm{wt} \%$ with the exception of Volara, which was about $4 \mathrm{wt} \%$. The water sorption values of stock or mouth-formed protectors were within this low value except for Bop Stopper $(22 \cdot 6 \%)$, made from a polymer foam and those with a liner: Den Pak $(0.36 \%)$, Doublegard liner $(0.98 \%)$ and Shock Doctor $(0.67 \%)$.

The tear strengths of the sheet materials were high, $410-565 \mathrm{~N} \mathrm{~cm}^{-1}$, except for Volara (white) with a value of $68 \mathrm{~N} \mathrm{~cm}^{-1}$. Although not reported in Table 3, no significant difference was found in tear strength between dry samples at $37^{\circ} \mathrm{C}$ and those at equilibrium with water at $37^{\circ} \mathrm{C}$.

Impact tests at room temperature showed that the sheet materials absorbed $80-90 \%$ of the impact and that testing at $37^{\circ} \mathrm{C}$ increased the percentage absorbed

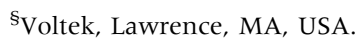

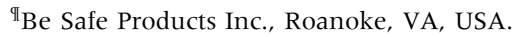

**Research Drive, Strathford, CT, USA.

${ }^{+\dagger}$ Masel Industries Inc., Bristol, PA, USA.

${ }^{\ddagger \ddagger}$ Brimms Inc., Tonawanda, NY, USA.

${ }^{\S} \mathrm{E}-\mathrm{Z}$ Gard Industries Inc., Minneapolis, MN, USA. 
only slightly. The calculated impact absorbed ranged from 90 to $102 \mathrm{~N}-\mathrm{cm}$. Impact tests on custom-fabricated mouth protectors (Table 4) from sheets of three suppliers confirmed the values on the sheets with $83-89 \%$

Table 4. Impact tests on custom fabricated mouth protectors

\begin{tabular}{|c|c|c|}
\hline Product & $\%$ absorption & $\begin{array}{l}\mathrm{N}-\mathrm{cm} \\
\text { absorption }\end{array}$ \\
\hline \multicolumn{3}{|l|}{ Glidewell } \\
\hline Clear 3-Layer Laminate & $73 \cdot 4(2 \cdot 3)$ & $82 \cdot 9(2 \cdot 6)$ \\
\hline \multicolumn{3}{|l|}{ Proform } \\
\hline Blue $0 \cdot 15$ & $87 \cdot 0(0 \cdot 7)$ & $98 \cdot 3(0 \cdot 8)$ \\
\hline Red $0 \cdot 15$ & $87 \cdot 8(0 \cdot 4)$ & $99 \cdot 2(0 \cdot 5)$ \\
\hline Red-White-Blue 0.15 Laminate & $83 \cdot 6(0 \cdot 9)$ & $94 \cdot 5(1 \cdot 0)$ \\
\hline Red $0 \cdot 2$ Laminate & $85 \cdot 8(1 \cdot 6)$ & $97 \cdot 0(1 \cdot 8)$ \\
\hline Orange $0 \cdot 2$ Laminate & $84 \cdot 2(0 \cdot 8)$ & $95 \cdot 1(0 \cdot 9)$ \\
\hline Blue $0 \cdot 2$ Laminate & $85 \cdot 4(1 \cdot 7)$ & $96.5(1.9)$ \\
\hline Green $0 \cdot 2$ Laminate & $85 \cdot 2(1 \cdot 1)$ & $96 \cdot 3(1 \cdot 2)$ \\
\hline \multicolumn{3}{|l|}{ StaGuard } \\
\hline Clear & $83 \cdot 0(1 \cdot 4)$ & $93 \cdot 8(1 \cdot 6)$ \\
\hline Yellow & $89 \cdot 2(0 \cdot 8)$ & $100 \cdot 8(0 \cdot 9)$ \\
\hline Blue & $85 \cdot 4(1 \cdot 1)$ & $96 \cdot 5(1 \cdot 2)$ \\
\hline
\end{tabular}

absorption of impact except for Glidewell at 73\% (probably because they contained the hard insert of PVCs). A recent study by Westerman et al. (2000) confirm the decrease when hard inserts are used. The impact absorbed ranged from 83 to $101 \mathrm{~N}-\mathrm{cm}$.

The impact values on stock and mouth-formed protectors are listed in Table 5. The percentages of impact absorbed ranged from 73 to $93 \%$, with Bop Stopper having the highest value of $93 \%$. The impact absorbed varied from about $80-105 \mathrm{~N}-\mathrm{cm}$.

\section{Discussion}

Based on these data and the success of these mouth protectors in preventing injuries (Craig \& Godwin, 1967), we recommend the Shore ' $A$ ' hardness of sheet material and the shell of stock or mouth-formed protectors shall be between 55 and 85 , and from 40 to 60 for the liners when measured at body temperature $\left(37^{\circ} \mathrm{C}\right)$. For comparison, Shore 'A' values for polyvinylacetate-polyethylene sheets available in the 1960s were 90 for DuraGuard, 75 for ProTex and 67 for

Table 5. Properties of stock and mouth-formed protectors

\begin{tabular}{|c|c|c|c|c|}
\hline \multirow[b]{2}{*}{ Product } & \multirow{2}{*}{$\begin{array}{l}\text { Shore 'A' hardness } \\
\text { at } 37^{\circ} \mathrm{C}\end{array}$} & \multirow{2}{*}{$\begin{array}{l}\text { Water sorption* } \\
\text { wt. } \% \text { at } 37^{\circ} \mathrm{C}\end{array}$} & \multicolumn{2}{|c|}{ Impact tests, room temperature* } \\
\hline & & & $\%$ absorbed & $\mathrm{N}-\mathrm{cm}$ absorbed \\
\hline Bop Stopper & $32(1)$ & $22 \cdot 6(0 \cdot 9)$ & $93(2)$ & $105(3)$ \\
\hline \multicolumn{5}{|l|}{ Den Pak } \\
\hline Shell & $63(0)$ & & & \\
\hline Liner & $26(1)$ & $0 \cdot 36(0.03)$ & $72 \cdot 3(3 \cdot 0)$ & $81 \cdot 7(3 \cdot 4)$ \\
\hline \multicolumn{5}{|l|}{ Doublegard } \\
\hline Shell & $78(4)$ & $0 \cdot 17(0 \cdot 02)$ & & \\
\hline Liner & $50(3)$ & $0.98(0.07)$ & $86(0 \cdot 6)$ & $97(0 \cdot 7)$ \\
\hline Jesco & $81(1 \cdot 4)$ & & $80 \cdot 1(1 \cdot 4)$ & $90 \cdot 5(1 \cdot 6)$ \\
\hline Scott AllSports & $75 \cdot 5(2 \cdot 1)$ & $0 \cdot 17(0 \cdot 02)$ & $90 \cdot 7(2 \cdot 0)$ & $102 \cdot 5(2 \cdot 3)$ \\
\hline Shield 12's \#1050 & $72 \cdot 8(1 \cdot 2)$ & $0 \cdot 18(0 \cdot 02)$ & $91 \cdot 0(1 \cdot 3)$ & $102 \cdot 8(1 \cdot 5)$ \\
\hline Shield 25's \#120 & $74 \cdot 1(1 \cdot 9)$ & $0 \cdot 16(0 \cdot 01)$ & $85 \cdot 1(1 \cdot 0)$ & $96 \cdot 2(1 \cdot 5)$ \\
\hline Shield 50's \#180 & $70 \cdot 9(1.5)$ & $0 \cdot 19(0 \cdot 03)$ & $90 \cdot 2(2 \cdot 1)$ & $101 \cdot 9(2 \cdot 4)$ \\
\hline \multicolumn{5}{|l|}{ Shield 2000} \\
\hline Shell & $76 \cdot 9(0 \cdot 8)$ & & & \\
\hline Liner & $47 \cdot 3(0 \cdot 5)$ & $0 \cdot 20(0 \cdot 02)$ & $87 \cdot 5(1 \cdot 2)$ & $98.9(1.4)$ \\
\hline Shield Youth & $57 \cdot 0(1 \cdot 9)$ & $0 \cdot 24(0 \cdot 02)$ & $92 \cdot 8(0 \cdot 8)$ & $104 \cdot 9(0 \cdot 9)$ \\
\hline \multicolumn{5}{|c|}{ Shield Lip and Mouth Protector } \\
\hline Lip & $74 \cdot 5(0 \cdot 6)$ & & & \\
\hline Mouth & $75 \cdot 6(1 \cdot 1)$ & $0 \cdot 20(0 \cdot 01)$ & $73 \cdot 1(7 \cdot 3)$ & $82 \cdot 6(8 \cdot 3)$ \\
\hline \multicolumn{5}{|l|}{ Shock Doctor } \\
\hline Shell & $77(1 \cdot 4)$ & & & \\
\hline Liner & $50(1 \cdot 4)$ & $0 \cdot 69(0.07)$ & $87(1)$ & $98(1)$ \\
\hline Tru-fit & $77 \cdot 5(0 \cdot 6)$ & $0 \cdot 17(0.05)$ & $93 \cdot 5(2 \cdot 1)$ & $105 \cdot 7(2 \cdot 4)$ \\
\hline
\end{tabular}

*Values are those for the entire mouth protector. 
StaGuard. ${ }^{\text {III }}$ Gardex, a latex rubber, had a value of 35 when fabricated into a sheet (Craig \& Godwin, 1967).

The impact results indicate that most of the mouth protector sheets, the fabricated mouth protectors, or the stock or mouth-formed protectors, when tested as indicated, absorbed more than $80 \%$ of the impact which corresponds to about $90 \mathrm{~N}-\mathrm{cm}$. However, based on reports of injuries (Craig \& Godwin, 1967), a minimum of $70 \%$ would probably be acceptable.

Early values for percentage energy absorption are not directly comparable because the energy at impact was 55 N-cm (Craig \& Godwin, 1967). However, values of percentage energy absorption on sheets of DuraGuard, ProTex, StaGuard and Gardex were 62, 84, 56 and 37\%, respectively. A later study (Godwin $\&$ Craig, 1968) of the percentage energy absorption on mouth protectors reports values from 60 to $92 \%$ with most of the values being $80 \pm 4$ except for the latex protector at about $60 \%$.

The tear strengths on the sheet materials, generally were greater than $400 \mathrm{~N} \mathrm{~cm}^{-1}$; however, materials with values greater than $200 \mathrm{~N} \mathrm{~cm}^{-1}$ at $37^{\circ} \mathrm{C}$ should provide adequate service life (Craig \& Godwin, 1967). Again, for comparison, tear strength values of early materials were 464, 286, 250 and 286 for DuraGuard, ProTex, StaGuard and Gardex, respectively. A later laboratory study (Godwin et al., 1982) of StaGuard and Proform reported tear strengths of 240 and $320 \mathrm{~N} \mathrm{~cm}^{-1}$, respectively, with no significant changes in values after being worn by junior football players, ages 9-12.

The water sorption for most mouth protectors and sheets was $<0.3 \mathrm{wt} \%$, and thus a maximum value of $0.5 \mathrm{wt} \%$ should provide reasonable freedom from penetration of oral fluids and organisms and allow for easy disinfection. The present values for water sorption cannot be compared with the earlier values because the values for Dura Guard, ProTex and StaGuard were measured in $\mathrm{mg} \mathrm{cm}^{-2}$ in the earlier study (Craig \& Godwin, 1967). If a density of $0.9 \mathrm{~g} \mathrm{~cm}^{-3}$ is taken for the sheets, estimated values for water sorption are $0.04 \%$ for Dura Guard, and $0.22 \%$ for ProTex and StaGuard.

Based on these suggestions, only Volara sheet, the Bop Stopper protector and the liner of Den Pak would be outside the limits for Shore ' $\mathrm{A}$ ' hardness. With respect to water sorption, Volara sheet and the Bop Stopper and Shock Doctor protectors absorbed more than the recommended limit of $0.5 \mathrm{wt} \%$. The minimum suggested tear strength of $200 \mathrm{~N} \mathrm{~cm}^{-1}$ was exceeded by all sheet material except Volara. All the sheet materials and custom fabricated protectors as well as the stock and mouth-formed protectors absorbed a greater percentage of the impact than the minimum recommended value of $70 \%$.

The setting of the limits for the properties is based on the values that are available on most products that have a history of success. These limits are somewhat arbitrary and could be changed but additional clinical and field experience is needed before making them more restrictive.

\section{Conclusions}

Based on the properties of athletic mouth protectors and materials, recommended limits should be as follows to provide adequate service:

(i) Shore 'A' hardness: Liner $40-60$ at $37{ }^{\circ} \mathrm{C}$,

Shell $55-85$ at $37^{\circ} \mathrm{C}$,

(ii) Water sorption: $<0.5 \mathrm{wt} \%$ at $37^{\circ} \mathrm{C}$,

(iii) Water solubility: No requirement,

(iv) Impact: $>70 \%$ absorbed at room temperature,

(v) Tear strength: $>200 \mathrm{~N} \mathrm{~cm}^{-1}$ at $37{ }^{\circ} \mathrm{C}$.

\section{References}

American Society for Testing Materials (1994a) Indentation hardness of rubber and plastics by means of a durometer, D2240. In ASTM Standards, Vol. 9.01, Philadelphia, PA.

American Society for Testing Materials (1994b) Strength of conventional vulcanized rubber and thermoplastic elastomers, D624-91. In ASTM Standards, Vol. 9.01, Philadelphia, PA.

Craig, R.G. \& Godwin, W.C. (1967) Physical properties of materials for custom-made mouth protectors. Michigan State Dental Journal, 49, 34.

Godwin, W.C. \& CRAIG, R.G. (1968) Stress transmitted through mouth protectors. American Dental Association Journal, 77, 1316.

Godwin, W.C., Craig, R.G., Koran, A., LANG, B.R. \& Powers, J.M. (1982) Mouth protectors in junior football players. Physicians Sportsmedicine, 10, 41 .

Westerman, B., Stringfellow, P.M. \& Eccleston, J.A. (2000) The effect on energy absorption of hard inserts in laminated EVA mouthguards. Australian Dental Journal, 45, 21.

Correspondence: Dr Robert G Craig, Department of Biologic and Materials Science, School of Dentistry, University of Michigan, Ann Arbor, MI 48109-1078, USA.

\footnotetext{
${ }^{\mathbb{I I I}}$ Buffalo Dental Manufacturing, Syosset, NY, USA.
} 